\title{
Regulatory Focus as a Predictor of Attitudes Toward Partitioned and Combined Pricing
}

Kiljae Lee

Jungsil Choi

Cleveland State University, j.choi59@csuohio.edu

Yexin J. Li

Follow this and additional works at: https://engagedscholarship.csuohio.edu/bus_facpub

Part of the Marketing Commons

How does access to this work benefit you? Let us know!

\section{Publisher's Statement}

NOTICE: this is the author's version of a work that was accepted for publication in Journal of Consumer Psychology. Changes resulting from the publishing process, such as peer review, editing, corrections, structural formatting, and other quality control mechanisms may not be reflected in this document. Changes may have been made to this work since it was submitted for publication. A definitive version was subsequently published in Journal of Consumer Psychology, 24, 3, (2014), DOI:10.1016/j.jcps.2014.01.001

\section{Original Published Citation}

Lee, K., Choi, J., Li, Y. J. (2014). Regulatory Focus as a Predictor of Attitudes Toward Partitioned and Combined Pricing. Journal of Consumer Psychology, 24(3), pp. 355-362.

This Article is brought to you for free and open access by the Monte Ahuja College of Business at EngagedScholarship@CSU. It has been accepted for inclusion in Business Faculty Publications by an authorized administrator of EngagedScholarship@CSU. For more information, please contact library.es@csuohio.edu. 


\title{
Regulatory focus as a predictor of attitudes toward partitioned and combined pricing
}

\author{
Kiljae Lee ${ }^{a}$, Jungsil Choi ${ }^{b, *}$, Yexin Jessica $\mathrm{Li}^{\mathrm{c}}$ \\ a College of Business, Embry-Riddle Aeronautical University Address: 600 S. Clyde Morris Blvd. Daytona Beach, FL 32114 \\ ' Department of Marketing. Monte Ahuja College of Business, Cleveland State University, 2121 Euclid Ave, Cleveland, OH, 44115, USA \\ 'Department of Marketing, School of Business, University of Kansas, 1300 Sunnyside Ave, Lawrence, KS, 66045, USA
}

\section{Introduction}

Whether making purchases online or in person, people often come across prices that are split into two or more quantities. For example, an infomercial may tout a product with a base price of just $\$ 15$, but with a shipping and handling fee of $\$ 4.95$. Similarly, a Las Vegas hotel may charge $\$ 99$ for a room, but guests must also pay a mandatory $\$ 10$ "resort fee". These companies could charge a single combined price of $\$ 19.95$ or $\$ 109$, respectively, but instead choose to display arguably more complicated partitioned prices instead.

Such examples of partitioned pricing are ubiquitous and becoming even more common as technological advances allow for more and different ways of displaying price information to customers. Morwitz, Greenleaf, Shalev, and Johnson (2009) examined ways in which partitioned pricing has changed over

\footnotetext{
* Corresponding author.

E-mail addresses: kjlee@ku.edu, Kay.Lee( jungsilchoi@gmail.com (J. Choi), Jessica.Li@@ku.edu (Y.J. Li).
}

the last 10-15 years. They found that companies have increased both the types of surcharges issued and the amount of money charged in extra fees. The hotel industry, for instance, made over 3 times more money in the form of surcharges from 2005 to 2007, from about $\$ 650$ million to $\$ 2$ billion dollars (Pugh, 2008).

The increased use of partitioned pricing can be attributed to perceptions of its effectiveness. However, there are situations in which combined pricing may be just as, or even more, effective than partitioned pricing. For instance, individuals with high need for cognition (NFC; Cacioppo, Petty, \& Feng Kao, 1984) tend to pay more attention to surcharges and their reasonableness. Therefore, they are sometimes less willing to purchase products that have partitioned rather than combined prices, i.e. when they deem the surcharges to be unreasonable (Burman \& Biswas, 2007).

Such findings suggest the importance of understanding boundary effects when considering when and why partitioned pricing is effective. However, research in this area is currently quite limited. Besides the aforementioned work on need for cognition, Morwitz et al. (2009) reference only three other areas that have 
received any attention when it comes to the ways in which buyer characteristics moderate the effectiveness of partitioned pricing brand attitudes (Morwitz, Greenleaf, \& Johnson, 1998), buyer's skepticism about firm's motives for partitioned pricing (Schindler, Morrin, \& Bechwati, 2005), and buyer experience (Cheema, 2008; Clark \& Ward, 2008). There has been no research on how goals affect the effectiveness of partitioned pricing. The current research aims to fill this gap in the literature. We suggest that regulatory focus can influence the effectiveness of partitioned pricing. In the next sections, we discuss extant findings on partitioned pricing and regulatory focus theory, followed by our hypotheses.

\section{Theoretical background and hypotheses development}

\section{Partitioned pricing}

In line with previous research, we define partitioned pricing as "a strategy that divides a product's price into a base price, charged for the product itself, and a mandatory surcharge(s) for products, services, fees, or taxes associated with purchasing or using the product" (Morwitz et al., 2009). A critical feature of partitioned pricing, which distinguishes it from other types of multicomponent pricing strategies, is that all surcharges are required. The opposing concept is combined pricing, which refers to charging a single price that includes all fees.

Much research in the pricing literature suggests partitioned pricing is more effective than combined pricing in increasing demand because people tend to underestimate surcharges and have significantly lower perceptions of the total cost when the price is offered in a partitioned rather than combined format (Clark \& Ward, 2008; Hossain \& Morgan, 2007; Lee \& Han, 2002; Morwitz et al., 1998). One explanation for why this occurs is based on the anchoring and adjustment heuristic (Tversky \& Kahneman, 1974). That is, people anchor on to a base price and insufficiently adjust upward for surcharges (Morwitz et al., 1998). Consumers are more susceptible to the anchoring and adjustment heuristic when they do not fully process surcharge information, and less susceptible when they attend carefully to all the price information presented.

The purpose of the current research is to examine the moderating role of regulatory focus on the effectiveness of partitioned pricing. We hypothesize that, in general, promotion focused consumers view partitioned prices more favorably than combined prices because they engage in global processing and pay less attention to surcharges. Several studies suggest a relationship between promotion focus and global processing (e.g. Förster \& Higgins, 2005), and it is hypothesized that global processing leads people to focus on the most relevant piece of information when making judgments, paying less attention to subsidiary or less important information. The following section spells out our reasoning in more depth.

\section{Information processing style, regulatory focus, and effect on partitioned pricing}

People tend to engage in either global processing ("seeing the forest") or local processing ("seeing the trees") when evaluating perceptual information (Navon, 1977). Global processing is believed to be important in understanding ambiguous, complex, and abstract stimuli. Individuals who engage in global processing tend to rely more on the primary, or most relevant, features of a stimulus when making judgments (Trope \& Liberman, 2000, 2010). In partitioned pricing, the main price is the largest charge and also the most relevant fee to the product itself. Thus, we hypothesize that global processing leads individuals to focus on the base price while ignoring or insufficiently processing surcharge information.

Local processing, on the other hand, is important for evaluating details and more minor information. Research finds that individuals who use local processing attend more to peripheral features than primary features (Trope \& Libernan, 2000, 2010). We hypothesize that when individuals use local processing to evaluate pricing information, they will attend to all details of the price, including subsidiary costs. In this situation, consumers are less susceptible to the anchoring and adjustment heuristic for partitioned pricing and more accurate in their assessment of the total cost. Formally, we hypothesize the following relationship between information processing and partitioned pricing;

H1. Global processing leads consumers to perceive partitioned pricing as more attractive than combined pricing while local processing leads partitioned pricing and combined pricing to be perceived as similarly attractive.

Regulatory focus theory proposes that there are two main ways in which people achieve the fundamental goals of seeking pleasure and avoiding pain - by being either promotion focused or prevention focused (Brockner, Higgins, \& Low, 2004; Higgins, 1997). Promotion focused individuals approach their goals with eagemess (Crowe \& Higgins, 1997; Freitas \& Higgins, 2002), and tend to place more emphasis on accomplishments and aspirations than safety and responsibilities (Higgins, 1997). Prevention focused individuals, on the other hand, are vigilant of potential losses and generally more concemed about duties and obligations than self-fulfillment (Crowe \& Higgins, 1997; Kirmani \& Zhu, 2007). Put another way, promotion focused individuals place more importance on what they "want" to do, while prevention focused individuals place more emphasis on what they should, or "ought" to do.

We posit that regulatory focus will affect the effectiveness of partitioned pricing because of the different information processing styles that promotion versus prevention foci elicit. The link between information processing style and regulatory focus is robust and reasonably well established. Förster and Higgins (2005) suggested that local processing fits a prevention focus on security because vigilant encoding of concrete details is crucial to maintaining safety; by contrast, global processing fits a promotion focus on advancement because concentrating on and details is insufficient perhaps even detrimental to progress. The authors conducted two studies to test their hypotheses. They found that promotion (prevention) focus increases processing of global (local) stimuli, and that experimentally priming global (local) processing leads to greater preferences for promotion (prevention) focus. While the authors contend that the relationship between regulatory 
focus and information processing style is reciprocal, they did not experimentally test causality by manipulating regulatory focus. Study 1 aims to conduct this test, with the following hypothesis;

H2. Promotion focus leads to more global processing than prevention focus.

If promotion focused individuals process information globally and attend more to primary information, they should be more susceptible to the anchoring and adjustment heuristic by anchoring on to the base price of a partitioned price and insufficiently adjusting upward for (or neglecting to attend at all to) subsidiary costs. Partitioned prices should appear more attractive than combined prices in this case. Prevention focused individuals, on the other hand, are hypothesized to process information locally by paying attention to details and subsidiary information. They are more likely to attend to and process not just the base portion of a partitioned price, but surcharges and other costs as well. Since partitioned pricing is effective mainly when consumers do not fully process the information associated with surcharges (Morwitz et al., 1998), this leads us to formulate the following hypothesis;

H3. Partitioned versus combined pricing is more effective for promotion focused individuals but there will be no difference in evaluations of partitioned and combined pricing for prevention focused consumers.

Four studies were conducted to test these hypotheses. Study 1 measures how regulatory focus affects information processing style. Study 2 manipulates global and local processing to examine their effect on consumer attitudes toward partitioned and combined pricing. Studies 3 and 4 test our main argument that regulatory focus affects the effectiveness of partitioned and combined prices for two types of products.

\section{Study 1: the effect of regulatory focus on global processing}

Research by Förster and Higgins (2005) provides strong evidence for the idea that global processing fits a promotion focus, whereas local processing fits a prevention focus. However, the experimental piece of their research looked only at the effect of information processing on regulatory orientation, not the other way around (though the authors suggest a reciprocal relationship between the two variables). Since the current research hypothesizes that promotion (prevention) focus leads individuals to processing information more globally (locally), Study 1 was conducted as a direct test of how primed regulatory focus affects information processing style.

\section{Participants and procedure}

124 college students from a large university in the Midwest participated in the study for partial course credit. Participants entered the lab in groups of up to 10 and were seated at computer stations partitioned for privacy. They were randomly assigned to one of two regulatory focus primes. Following Freitas and
Higgins (2002) procedure, promotion focus was primed by asking participants to imagine their past and current hopes, dreams, and aspirations. Prevention focus was primed by asking participants to think about their duties, obligations, and responsibilities. Immediately after the prime, participants answered a manipulation check question [what is more important for you to do? something I ought to (1) something I want to (7)]. This manipulation check item has been used successfully in previous research (Chatterjee, Malshe, \& Heath, 2010; Chatterjee, Roy, \& Malshe, 2011; Keller, 2006).

Next, participants were asked to participate in a cognitive psychology study, which was intended to measure information processing using methods adapted from Kimchi and Palmer (1982). In this task, participants were shown 12 target figures and asked to indicate whether each figure was more similar to a group of objects that matched its global shape or to a group of objects that matched its local components. The number of times participants matched the shapes on the basis of their global form rather than their local details was calculated and served as the dependent variable, with higher numbers indicating relatively greater global processing.

\section{Results}

Manipulation check. The results of the manipulation check suggested that the regulatory focus primes were effective. Compared to those primed with prevention focus, people primed with promotion focus assigned more weight to things they want, rather than ought, to do $\left(M_{\text {promotion }}=4.32(S D=1.615), M_{\text {prevention }}=\right.$ $3.70(S D=1.585), t(122)=2.13, p=.035)$.

Information processing style. Results revealed a significant effect of regulatory focus on information processing style, $t(122)=2.07, p=.040$. Specifically, people primed with promotion focus made more global choices than people primed with prevention focus $\left(M_{\text {promotion }}=9.13, S D=2.41 ; M_{\text {prevention }}=\right.$ $8.20, S D=2.59$ ). This finding supports $\mathrm{H} 2$.

\section{Study 2: information processing style and attitudes toward partitioned pricing}

Study 2 tests the hypothesis that information processing style affects attitudes toward partitioned and combined pricing. We predict that global processing leads people to find partitioned pricing more attractive than combined pricing while local processing leads people to evaluate the two pricing types similarly.

\section{Participants and procedure}

The study had a 2 (information processing: global vs. local) $\times 2$ [(pricing type: partitioned pricing, $\$ 34.99+\$ 11.00$ (handling and delivery) vs. combined pricing, \$45.99)] between subjects design. Participants were recruited using the online survey website Mechanical Turk, and randomly assigned to one of two information processing style conditions (global vs. local). Global and local processing were manipulated using previously established procedures (Friedman, Fishbach, Förster, \& Werth, 2003). Following their procedure, all participants were asked to 
look at a map of Europe on a computer screen and examine it for three minutes. Participants in the global processing condition were asked to look at the map as a whole and told that they would answer questions about the overall shape of the map later. Participants in the local processing condition were asked to look at the details of the map and told that they would answer questions about details of the map later. Twenty-eight participants who failed to follow instructions and did not look at the map for three minutes were excluded, leaving a sample of 99 participants. After finishing this part of the study, participants were told that they would be participating in an unrelated marketing survey about consumer behavior.

In the second part of the study, participants were asked to imagine purchasing flowers online for their significant other's birthday. They were presented with a picture and the price of a medium size flower arrangement. Participants in the partitioned pricing condition were told that the offer price for the flowers is $\$ 34.99$ plus $\$ 11.00$ for handling and delivery. Participants in the combined pricing condition were simply told that the offer price is $\$ 45.99$.

Next, participants responded to how attractive they perceived the offer price to be using two items on seven-point scales (very unattractive/very attractive, very undesirable/very desirable). Because of the high degree of conceptual and statistical overlap $(r=.79, p<.001)$, these two items were aggregated and served as our dependent variable of interest in the subsequent analysis.

\section{Results}

We predicted a pricing type by information processing interaction whereby global processing (but not local processing) would lead people to perceive partitioned pricing to be more attractive than combined pricing. Our hypothesis was supported by a significant interaction effect, $F(1,95)=4.32, p=.040, \eta^{2}=$ .043 . Pairwise comparisons showed that partitioned pricing was perceived to be more attractive than combined pricing for people primed with global processing $\left(M_{\text {partitioincd }}=5.48, M_{\text {combined }}=\right.$ 4.64, $\left.F(1,95)=5.06, \quad p=.027, \quad \eta^{2}=.051\right)$, supporting $\mathrm{H} 2$. However, no difference in perceived attractiveness existed for people primed with local processing $\left(M_{\text {partitioined }}=5.04\right.$, $\left.M_{\text {combined }}=5.26, F(1,95)<1, p>.52, \eta^{2}=.004\right)$ (see Fig. 1).

\section{Study 3: regulatory focus and furniture prices}

In Study 3, we examine how different regulatory foci affect the attractiveness and purchase intention of products with partitioned and combined pricing. We predict that promotion focused individuals will find partitioned prices more attractive than combined prices and be more willing to purchase products with partitioned prices. Prevention focused individuals, on the other hand, should exhibit no such bias.

\section{Participants and procedure}

One-hundred and one undergraduate students from a large public university in the Midwest participated in the study for

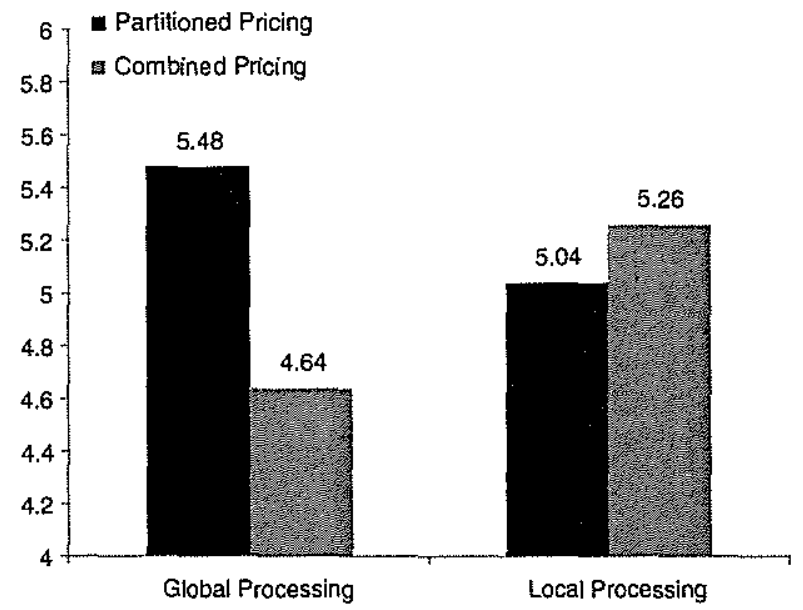

Fig. 1. Primed information processing style affects the relative attractiveness of partitioned and combined pricing (Study 2).

partial course credit. The study had a 2 [pricing type: partitioned $(\$ 489.99+\$ 40$ for handling and delivery) versus combined $(\$ 529.99)] \times 2$ (regulatory focus: promotion versus prevention) between subjects design. Participants entered the lab in groups of up to 10 at a time and were seated at computers partitioned for privacy. They were randomly assigned to a regulatory focus prime. Following Freitas and Higgins (2002), regulatory focus was primed by asking participants either to imagine their past and current hopes, dreams, and aspirations (promotion focus) or to imagine their duties, obligations, and responsibilities (prevention focus). Immediately afterward, participants answered a manipulation check question [i.e., what is more important for you to do? something I ought to (1) something I want to (7)].

Next, participants were told that they would be completing an unrelated study about advertising. Participants were told to assume that they are buying sofa set to replace an old one that they had, and were presented with one of two advertisement stimuli. Both stimuli consisted of a photo of the sofa set, a list of the sofa set's features, and the sofa set's price. The stimuli were identical except for how the price was presented. In the combined pricing condition, the price was presented as $\$ 529.99$. In the partitioned pricing condition, the base price (\$489.99) was presented separately from a mandatory delivery and handling charge of $\$ 40$.

After looking at the advertisement, participants rated the attractiveness of the sofa set offer using two items on seven-point scales (i.e., overall, the store's offer is very unattractive (1) very attractive (7); very undesirable (1) very desirable (7), $r=.84$, $p<.001$ ). They also indicated their likelihood of purchasing the sofa set using three-items on seven-point scales (the likelihood of my purchasing the product is; the probability that I would consider buying the product is; and my willingness to buy the product is; very low (1) very high $(7) ; \alpha=.95)$.

\section{Results}

Manipulation check. The manipulation check showed that the regulatory focus primes were successful; those primed with promotion focus (vs. prevention focus) associated more 
importance with want than ought $\left(M_{\text {promotion }}=4.4, M_{\text {prevention }}=\right.$ $3.27, t(99)=2.95, p=.004)$.

Attractiveness of offer. There was a significant main effect of pricing type on the attractiveness of the sofa offer $(F(1,97)=$ $\left.4.75, p=.032, \eta^{2}=.047\right)$; partitioned pricing was rated higher in attractiveness than combined pricing. No main effect of regulatory focus was found $\left(F(1,97)<1, p>.80, \eta^{2}=.001\right)$. More integral to our hypothesis, the interaction of pricing type and regulatory focus was significant $(F(1,97)=8.37, p=.005$, $\eta^{2}=.079$ ). Pairwise comparisons showed that partitioned pricing was more attractive than combined pricing when participants were primed with promotion focus $\left(M_{\text {partitioned }}=5.55, M_{\text {combined }}=\right.$ $\left.3.96, F(1,97)=12.65, p=.001, \eta^{2}=.115\right)$. However, no significant difference in attractiveness ratings was found for participants primed with prevention focus $\left(M_{\text {partitioned }}=4.72\right.$, $\left.M_{\text {combined }}=4.94, F(1,97)<1, p>.61, \eta^{2}=.003\right)$. These results support $\mathrm{H} 3$ (see Fig. 2).

Purchase likelihood. A significant main effect of pricing type on purchase likelihood was found, $(F(1,97)=4.61, p=$ $\left..034, \eta^{2}=.045\right)$, whereby partitioned pricing was more effective at increasing purchase likelihood than combined pricing. The interaction between pricing type and regulatory focus on purchase likelihood, however, was not statistically significant $(F(1,97)=1.49, p>.22)$. However, the pattern of results was in the predicted direction and pairwise comparisons support hypothesis 3 . That is, partitioned pricing was more effective at enhancing purchase likelihood than combined pricing when participants were primed with promotion focus ( $M_{\text {partitioned }}=4.44, M_{\text {combined }}=$ $\left.3.43, F(1,97)=5.58, p=.02, \eta^{2}=.054\right)$. However, no significant difference in purchase likelihood was found for participants primed with prevention focus $\left(M_{\text {partitioned }}=4.57, M_{\text {combined }}=\right.$ $4.30, F(1,97)<1, p>.51)$.

\section{Study 4: Regulatory Focus and Plane Ticket Prices}

Study 3 provides support for the hypothesis that regulatory focus affects the perceived attractiveness of partitioned pricing. In order to increase external validity, Study 4 attempts to

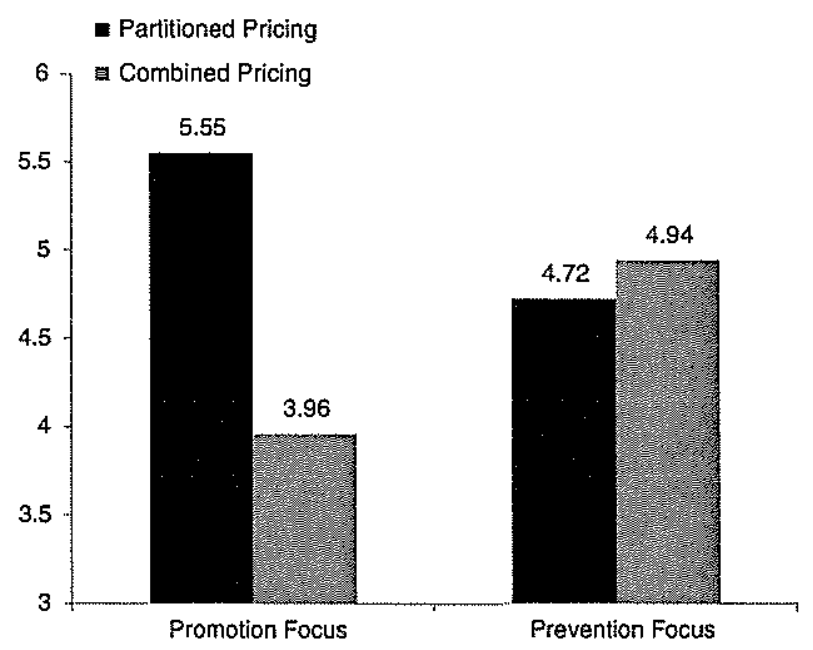

Fig. 2. Regulatory focus affects the relative attractiveness of partitioned and combined pricing for sofa sets (Study 3). replicate this finding with a different product that is arguably more relevant to our sample. We chose to use plane tickets rather than furniture as the product to be purchased in Study 4 because travel related expenses tend to be more personally relevant than sofa sets for college-aged consumers. To further increase purchase relevance in this study, we chose the most common airport students from our university fly out of as the origin of their trip.

\section{Participants and procedure}

126 undergraduate students from a large public university in the Midwest participated in the study for partial course credit. Participants entered the lab in groups of up to 10 and were seated at computer stations partitioned for privacy. The study had a 2 [pricing type: partitioned $(\$ 357+\$ 38)$ vs. combined $(\$ 395)] \times 2$ (regulatory focus: promotion vs. prevention) between subjects design. Regulatory focus was primed using the same method as Study 3. That is, participants in the promotion focus condition were asked to imagine their past and current hopes, dreams, and aspirations. Participants in the prevention focus condition were asked to imagine their duties, obligations, and responsibilities. The same manipulation check used in studies 2 and 3 was conducted immediately after the prime.

Next, participants were told to assume that they needed to make a trip to New York City. They were presented with price information for a round-trip airline ticket from a major city in the US to New York City. To enhance purchase relevance, the closest international airport to the university campus was chosen as the origin of travel. Participants in the combined pricing condition were told the ticket costs $\$ 395$; those in the partitioned pricing condition were told that the ticket costs $\$ 357$ plus an additional $\$ 38$ for tax and other surcharges. Participants rated the attractiveness of the offer using the same items in Study 3: [very unattractive (1) very attractive (7); very undesirable $(I) \sim$ very desirable $(7) ; r=.80, p<.001]$. They also rated their purchase likelihood using the same scale from Study 3 (the likelihood of my purchasing the product is; the probability that I would consider buying the product is; and my willingness to buy the product is; very low (1) very high $(7) ; \alpha=.94)$.

Results

Manipulation check. The manipulation check showed that regulatory focus was primed successfully. Participants primed with a promotion focus (vs. prevention focus) attached more importance to things they want to do rather than things they ought to do $\left(M_{\text {promotion }}=4.32, M_{\text {prevention }}=3.44, t(124)=\right.$ $3.00, p<.01)$.

Attractiveness of offer. Results revealed a significant main effect of pricing type $\left(F(1,122)=6.50, p=.012, \eta^{2}=.051\right)$, and a marginal main effect of regulatory focus $(F(1,122)=$ 2.79, $p=.098, \eta^{2}=.022$ ) on offer attractiveness. That is, participants in the partitioned (versus combined) pricing condition and the promotion (versus prevention) focused condition perceived the ticket offer to be more attractive. However, these 
main effects should be interpreted in light of their two-way interaction, $F(1,122)=2.98, p=.087, \eta^{2}=.024$. As in Study 3, pairwise comparisons showed that partitioned pricing was more attractive than combined pricing when participants were primed with promotion focus ( $M_{\text {partitioned }}=5.31, M_{\text {combined }}=4.29, p=$ $.003, \eta^{2}=.072$ ), but not when they were primed with prevention focus $\left(M_{\text {partitioned }}=4.50, M_{\text {combined }}=4.30, p>.56, \eta^{2}=.003\right)$ (Fig. 3). These results lend further support for $\mathrm{H} 3$.

Purchase likelihood. In line with previous research, there was a significant main effect of pricing type on purchase likelihood $\left(F(1,122)=7.06, p=.009, \eta^{2}=.055\right)$, whereby people were more likely to purchase products with partitioned than combined prices. The interaction effect between pricing type and regulatory focus was not statistically significant $(F(1,122)<1$, $p>.38$ ). The results of the pairwise comparisons, however, are consistent with hypothesis 3 . The results showed that partitioned pricing was more effective at enhancing purchase likelihood than combined pricing when participants were primed with promotion focus $\left(M_{\text {partitioned }}=5.23, M_{\text {combined }}=4.39, F(1,122)=6.45, p=\right.$ $.012, \eta^{2}=.050$ ). However, no significant difference in purchase likelihood was found for participants primed with prevention focus $\left(M_{\text {partitioned }}=4.50, M_{\text {combincd }}=4.07, F(1,122)=1.54, p>.21\right)$.

\section{General discussion}

Four studies provided consistent support for the hypothesis that regulatory focus affects the perceived attractiveness of partitioned pricing. Specifically, promotion focused individuals found partitioned prices more attractive than combined prices while prevention focused individuals rated the two types of pricing similarly attractive. Furthermore, we found evidence for the hypothesis that regulatory focus affects the perceived attractiveness of partitioned pricing through shifts in information processing style. Study 1 supports extant research on regulatory focus and information processing style by showing that promotion focus enhances global processing more than prevention focus does. Study 2 revealed that global processing

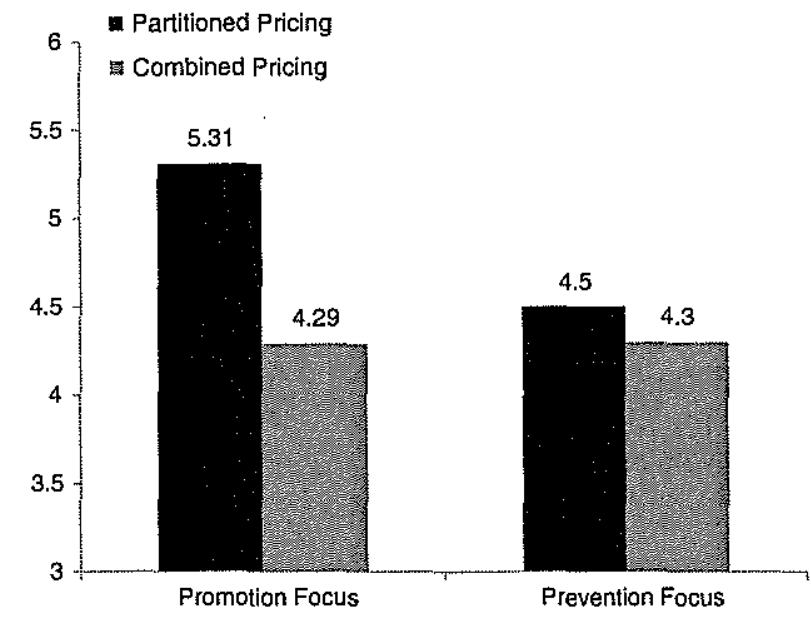

Fig. 3. Regulatory focus affects the relative attractiveness of partitioned and combined pricing for plane tickets (Study 4). leads people to find partitioned pricing more attractive than combined pricing, presumably because they are focusing on the main price component (i.e. the base price) without attending sufficiently to supplementary price information (i.e. surcharges). Studies 3 and 4 primed regulatory focus and found that promotion focused, but not prevention focused, individuals prefer partitioned pricing over combined pricing.

\section{Contributions and implications}

Although partitioned pricing has received increasing attention among academics over the last decade, and is being used more frequently by companies (especially in e-commerce), there is limited research on the ways in which buyer characteristics influence the attractiveness of this pricing type (Morwitz et al., 2009). The current research contributes to this literature by introducing regulatory focus theory as a variable that helps determine the effectiveness of partitioned versus combined pricing. Given the importance of understanding the effects of regulatory focus in marketing, we expect that the theoretical connection between regulatory focus and partitioned pricing that we proposed and tested here will invite other research on the topic.

The current research has implications for the design of promotional materials that include price information. Because price is such a critical component of consumer choice, it is important to know what pricing technique is best suited to a particular ad. Zliu and Meyers-Levy (2007) found that ads designed with higher levels of ambiguity are more persuasive for promotion-oriented individuals because they are more likely to engage in relational elaboration. Our findings suggest that such ads would benefit from the addition of partitioned pricing information. In a similar vein, Lee and Aaker (2004) showed that promotion focused gain-framed messages are effective and that prevention focused loss-framed messages are effective. Our findings suggest that pairing gain-framed promotion-oriented messages with partitioned pricing would be optimal. Other research has shown that certain products are more likely to be associated with promotion (vs. prevention) concerns (Mourali, Böckenholt, \& Laroche, 2007). Our findings suggest that it is especially important to use partitioned pricing for companies selling these products.

In contrast to other research suggesting partitioned pricing is the superior pricing strategy, the current research shows an instance when it may make more sense to use combined pricing. Partitioned pricing can negatively affect brand attitudes in the long run. This is most likely to happen when consumers realize their errors in interpreting the price and attribute the errors to the retailer (Lee \& Han, 2002). Companies must always balance the costs and benefits of adopting different pricing strategies, and the current research suggests using combined pricing for products with prevention concerns may be the better choice in the long run.

Furthermore, our findings might provide additional explanations for why the effectiveness of partitioned pricing is reduced when certain factors that increase surcharge salience exist. For example, when a seller's reputation is low, partitioned pricing is less effective because attention to 
surcharges is enhanced (Cheema, 2008). We suggest that low seller reputation turn on a red light, which leads consumers to become prevention focused and pay more attention to surcharges. It would be worthwhile for future research to investigate this proposed underlying mechanism. We believe our findings provide a theoretical bridge that might connect the gap between previous findings and future studies.

Finally, the current research has implications for consumer welfare. Since the effectiveness of partitioned pricing relies on undermining consumers' cognitive processing, some researchers have argued that its use can decrease perceived pricing fairness (Sheng, Bao, \& Pan, 2007). Thus, understanding the situations that make partitioned pricing more attractive may be an important tool for consumers to protect themselves from unsavory marketing schemes.

\section{Limitations and future directions}

One of the limitations of the present research is that we failed to find a significant interaction effect of regulatory focus and pricing type on purchase likelihood. However, post-hoc tests showed consistent results with our hypothesis that partitioned pricing is more effective than combined pricing for those who are promotion focused but not for those who are prevention focused. One of the potential reasons for the insignificant interaction effect is our asymmetric $2 \times 2$ experimental design. That is, a significant difference was expected only for the promotion focus condition but not for the prevention focus condition, which results in the prediction of an ordinal interaction. Compared to a crossover interaction, an ordinal interaction is more difficult to detect and requires greater statistical power. Furthermore, compared to attitudes (attractiveness of the offer), behavioral intention (purchase likelihood) is expected to have higher statistical variance and lower statistical power because more external factors, such as social norms, are considered in the decision (Wilson, Mathews, \& Harvey, 1975). It could be that the high price points of the products in our studies are barriers of purchase for many of the college students in our sample, increasing residual variation and making the interaction more difficult to detect.

It would be fruitful for future research to explore how other buyer characteristics influence the effectiveness of partitioned and combined pricing. Previous research has established a robust link between self construal and regulatory focus, whereby people with a dominant independent self construal are more likely to be promotion focused and those that have a dominant interdependent self are more likely to be prevention focused (Kitayama, Markus, Matsumoto, \& Norasakkunkit, 1997; Lee, Aaker, \& Gardner, 2000). Would the effectiveness of partitioned pricing, then, be especially strong in independent or individualistic cultures and attenuated in countries that are more interdependent or collectivistic?

It might also be worthwhile for other research to investigate different situational characteristics that affect information processing style and partitioned pricing. For example, positive mood induces global processing and negative mood induces local processing (Gasper \& Clore, 2002). Are people in a positive mood more susceptible to partitioned pricing?

\section{Summary}

In summary, the current research explores how an important factor in consumer behavior, regulatory focus, affects the perceived attractiveness of partitioned and combined pricing. The results of four studies are consistent in their support for the hypothesis that promotion focused (but not prevention focused) consumers find partitioned prices more desirable than combined prices. This research contributes to the pricing literature in several ways, and paves the way for future work on how buyer characteristics moderate the effectiveness of partitioned pricing.

\section{References}

Brockner, J., Higgins, E. T., \& Low, M. B. (2004). Regulatory focus theory and the entrepreneurial process. Joumal of Business Venturing, 19, 203-220.

Burman, B., \& Biswas, A. (2007). Partitioned pricing: Can we always divide and prosper? Journal of Retailing, $83,423-436$.

Cacioppo, J. T., Petty, R. E., \& Feng Kao, C. (1984). The efficient assessment of need for cognition. Journal of Personality Assessment, 48, 306-307.

Chatterjee, S., Malshe, A. V., \& Heath, T. B. (2010). The effect of mixed versus blocked sequencing of promotion and prevention features on brand evaluation: The moderating role of regulatory focus. Journal of Business Research, 63(12), 1290-1294.

Chatterjee, S., Roy, R., \& Malshe, A. V. (2011). The role of regulatory fit on the atraction effect. Jotunal of Consumer Psychology, 2J(4), 473-481.

Cheema, A. (2008). Surcharges and seller reputation. Joumal of Consumer Resermch, 35, 167-177.

Clark, J. M., \& Ward, S. G. (2008). Consumer behavior in online auctions: An examination of partitioned prices on eBay. Journal of Marketing Theory and Practice, 16, 57-66.

Crowe, E., \& Higgins, E. T. (1997). Regulatory focus and strategic inclinations: Promotion and prevention in decision-making. Organizational Behavior and Human Decision Processes, 69, 117-132.

Förster, J., \& Higgins, E. T. (2005). How global versus local perception fits regulatory focus. Psychological Science, 16, 631-636.

Freitas, A. L., \& Higgins, E. T. (2002). Enjoying goal-directed action: The role of regulatory fit. Psychological Science, 13, 1.

Friedman, R. S., Fishbach, A., Förster, J., \& Werth, L. (2003). Attentional priming effects on creativity. Creativity Research Jonmal, 15, 277-286.

Gasper, K., \& Clore, G. L. (2002). Attending to the big picture: Mood and global versus local processing of visual information. Psychological Science, I3(1), 34--40.

Higgins, E. T. (1997). Beyond pleasure and pain. American Psychologist, 52 , 1280.

Hossain, T., \& Morgan, J. (2007). ... plus stipping and handling: Revenue (non) equivalence in field experiments on ebay. The BE Journal of Economic Analysis \& Policy, 6 .

Keller, P. A. (2006), Regulatory focus and efficacy of health messages. Joumal of Consumer Resetich, 33(1). 109-114.

Kimchi, R., \& Palmer, S. E. (1982). Form and texture in hietarchically constructed patterns. Joumal of Experimental Psychology: Hzman Perception and Performance, 8, 521.

Kirmani, A., \& Zhu, R. (2007). Vigilant against manipuation: The effect of regulatory focus on the use of persuasion knowledge. Jonrnal of Marketing Research, $6880-70 \%$.

Kitayama, S., Markus, H, R., Matsumoto, H., \& Norasakkunkit, V. (1997). Indjvidual and collective processes in the construction of the self: self-cnhancement in the United States and self-criticism in Japan. Journal of Personality and Social Psychology, 72(6), 1245.

Lee, A. Y., \& Aaker, J. L. (2004). Bringing the frame into focus: The influence of regulatory fit on processing thency and persuasion. Journal of Personality and Social Psychology, \$6(2), 205. 
Lee, A. Y., Aaker, J. L., \& Gardner, W. L. (2000). Thic pleasures and pains of distinct self-construals: The role of interdependence in regulatory focus. Journal of Personality and Social Psychology, 78(6), 1122.

Lee, Y. H., \& Han, C. Y. (2002). Partitioned pricing in advertising: Effects on brand and retailer attitudes. Marketing Letters, 13, 27-40.

Morwitz, V., Greenleaf, E. A., \& Johnson, E. J. (1998). Divide and prosper: Consumers' reactions to partitioned prices. Jounal of Marketing Research, 453-463.

Morwitz, V., Greenleaf, E., Shalev, E., \& Johnson, E. (2009). The price does not include additional taxes, fees, and surcharges: A review of research on partitioned pricing. Available at SSRN: http://ssrn.conv/abstracl=1350004

Mourali, M., Böckenholt, U., \& Laroche, M. (2007). Compromise and attraction effects under prevention and promotion motivations. Journal of Consumer Research, 34(2), 234-247.

Navon, D. (1977). Forest before trees: The precedence of global features in visual percention. Cognitive Psychology, 9, 353-383.

Pugh, T. (2008, March 3). This costs you $\$ 9.22$ each year and companies are hoping that you'll never even notice. The Augusta Chronicle, Al.
Schindler, R. M., Morrin, M., \& Bechwati, N. N. (2005). Shipping charges and shipping-charge skepticism: Inplications for direct matketers' pricing formats. Joumal of Interactive Marketing, 19, 41-53.

Sheng, S., Bao, Y., \& Pan, Y. (2007). Partitioning or bundling? Perceived faimess of the surcharge makes a difference. Psychology and Marketing, 24, 1025-1041.

Trope, Y., \& Liberman, N. (2000). Temporal construal and time-dependent changes in preference. Joumal of Personality and Social Psychology, 79, 876.

Trope, Y., \& Liberman, N. (2010). Construal-level theory of psychological distance. Psychological Review, 117, 440.

Tversky, A., \& Kahneman, D. (1974). Judgment under uncertainty: Heuristics and biases. Science, I85, 1124 .

Wilson, D. T., Mathews, H. L., \& Harvey, J. W. (1975). An empirical test of the Fishbein behavioral intention model. Journal of Consumer Research, /(4), $39-48$.

Zhu, R. J., \& Meyers-Levy, J. (2007). Exploring the cognitive mechanism that underlies regulatory focus effects. Joumal of Consumer Research, 34(1), 89-96. 